Sharif University of Technology
Scientia Iranica
SCIENTIA
I RAN ICA
http://scientiairanica.sharif.edu

\title{
Investigating the behavior factor of coupled concrete shear walls with steel coupling beam
}

\author{
M.H. Daneshvar and A. Karamodin* \\ Department of Civil Engineering, Ferdowsi University of Mashhad, Mashhad, Iran.
}

Received 1 March 2017; received in revised form 3 October 2018; accepted 27 October 2018

\author{
KEYWORDS \\ Hybrid coupled shear \\ walls system; \\ Steel coupling beam; \\ Behavior factor; \\ Ductiltity factor; \\ Overstrength factor; \\ Coupling ratio; \\ Seismic response; \\ Inelastic behavior; \\ Numerical \\ simulations.
}

\begin{abstract}
The behavior factor is used to reduce ordinates of the elastic spectrum or the forces detected by linear analysis to take into account the non-linear structural properties. The more accurate this parameter is estimated, the more exact the responses of structures will be. Recently, coupled walls with steel coupling beams have been extensively utilized as an efficient system against lateral forces in high-rise buildings. However, there is not enough information about the behavior of these walls during earthquake, and design codes do not specify any specific behavior factor of this structural system. Consequently, this paper aims to find the behavior factor of this structural system. To this end, 6-, 12-, and 20 -story buildings were assessed. Except for the number of stories, these buildings shared the same characteristics. Building's height, length of coupling beams, and the coupling ratio were key parameters that influenced the behavior factor of the aforesaid structural system. In this work, the effect of these parameters on this factor was studied.
\end{abstract}

(C) 2020 Sharif University of Technology. All rights reserved.

\section{Introduction}

Recently, the coupled shear walls have been widely used as an efficient system that resists lateral loads on high-rise buildings [1]. This structural system includes several separate walls connected by beams. Beams are fixed to the walls. In this way, lateral stiffness of the structural system increases. Additionally, axial forces are induced by the adjacent connecting walls. Note that the centers of rigidity of walls are far from each other. As a result, the aforesaid forces induce a considerable moment, which reduces the internal moments of walls [2].

Following the Alaska earthquake in 1964, the coupling beams of existing shear walls were extensively

\footnotetext{
*. Corresponding author. Tel.: +985138806053 E-mail addresses: hasan.daneshvar@mail.um.ac.ir (M.H. Daneshvar); a-karam@um.ac.ir (A. Karamodin)
}

damaged. These damages considerably attracted the attention of researchers. Having conducted some experiments, they concluded that beams with usual reinforcing steel bars performed poorly during earthquakes. To remedy this, Paulay and Priestley [3] applied diagonal steel bars to the coupling beams. They concluded that the diagonal configuration of steel bars increased the efficiency of the coupled beam. Afterwards, Harries [4] experimentally assessed the behavior of these beams. Then, this researcher used steel coupling beams in walls because of their significant energy absorption and easy implementation. In comparison to concrete coupled beams, steel beams show a proper energy absorption capability. In 2001, Gong and Shahrooz [5] synthesized the existing information on hybrid coupled wall systems into helpful recommendations for seismic analysis and design of this structural system. In 2005, Su and Zhu [6] conducted experimental tests on the coupling beams reinforced by steel plates. The obtained results showed that use of these steel plates on both sides of the beams 
increased the ultimate resistance and energy absorption capacity of the beams. Nevertheless, the inducement of cracks in beams ceased the full composite action in the aforementioned systems. Moreover, Harries and McNeice [7] studied the behavior of coupling concrete shear walls. They concluded that the walls impinged on the structural behavior of upper stories of tall buildings. To remedy this, they suggested placing several beams at different height levels of the wall. In this way, the shear forces of the coupling beams were redistributed and the demand capacity was reduced. Note that higher modes contribute significantly to the structural behavior of the upper stories.

In 2006, Shen et al. [8] employed post-tensioned joints for connecting the steel beams to the shear walls. Afterwards, Fortney et al. [9] deployed a replaceable fuse steel coupling beam. Furthermore, El-Tawil et al. [10] investigated the behavior of the shear walls with steel coupling beams. In this work, they took advantage of a prescriptive method based on linear elastic analysis and an all-purpose performancebased method employed in conjunction with linear or nonlinear analysis techniques.

In some other research works, the behavior factor of adjacent structures joined by coupled beams with a coupling ratio has been investigated. Deng et al. [11] investigated the behavior of shear walls with steel truss beams under earthquake loading. In their research work, it was found that variations in the area and the angle of some elements affect the amount of wall coupling. In another research, Louzai and Abed [12] evaluated the seismic behavior coefficient of reinforced concrete structures and they found that changes of behavior coefficient detected by identical analysis methods were not the same. Moreover, Soltangharaei et al. [13] studied buildings exposed to a near-fault earthquake. They concluded that the behavior factor in near-fault records was $23 \%$ less than far-fault records, on average. In another research work conducted by Issa and Issa [14], the investigation of the behavior coefficient of the concrete frame buildings of three, five, and seven stories with SeismoStruct software showed that the value of the proposed behavior factor was lower than that of the corresponding behavior factor reported in Eurocode 8. The seismic behavior of tall hybrid coupled wall systems using nonlinear time history analysis was studied by Hung and $\mathrm{Lu} \mathrm{[15].} \mathrm{It} \mathrm{was}$ found that a tall coupled wall structure with uniform steel coupling beam sections over the structural height ultimately led to the average proportion of yielding coupling beams by about $80 \%$, which is consistent with beam design methods carefully tuned according to the vertical demand distribution determined by effective lateral load analysis.

The behavior of the coupled concrete shear walls with steel coupling beams has drawn considerable attention [16] and thus, different researchers have evaluated the structural systems [17]. However, to the extent of authors' knowledge, no behavior factor of these structural systems has been determined so far, perhaps because only limited experimental data are available about them. Note that the aforesaid factor demonstrates the inelastic deformations of structures under strong earthquakes. As a consequence, this paper deals with this issue. In what follows, the behavior factor of three similar buildings with different numbers of stories including 6-, 12-, and 20-story buildings is found. These structures are analyzed and designed based on ASCE7-05 [18], ACI318-05 [19], and recommendations for the seismic design of hybrid coupled walls [20]. In addition, the effect of various parameters such as height, coupling beam length, and coupling ratio on the behavior factor is assessed.

\section{Parameters influencing the behavior factor}

In the force-based seismic design, the force is extracted from spectra based on linear behavior and the use of a reduction factor, which changes the linear system into an equivalent one to account approximately for the nonlinear effects [21]. This force reduction factor or response modification factor, called behavior factor, has an important role in estimating the design force of the structures. Its value depends on the parameters that directly affect the energy dissipation capacity of the structure: ductility, added viscous damping, and strength reserves coming from its redundancy and the overstrength of individual members. Two wellknown approaches to computing the behavior factor are Uang [22] and ATC-19 [23] methods.

In Uang's method, the behavior factor emerges as follows [22]:

$$
R=\frac{C_{e u}}{C_{s}}=\frac{V_{e} / W}{V_{s} / W}=\frac{V_{e}}{V_{s}},
$$

where $V_{e}$ and $V_{s}$ are the maximum and the first significant yield base shears, respectively. In this approach, the principal period of the structure has no role.

According to ATC-19 proposal, the behavior factor can be computed through the following relation [23]:

$$
R=R_{\mu} \times R_{s} \times R_{r},
$$

where ductility factor, overstrength, and additional constraint factor are denoted by $R_{\mu}, R_{s}$, and $R_{r}$, respectively.

It is clear that ductility capacity, the fundamental period of the structure, overstrength, applied earthquake load, and the characteristics of the bedrock affect the behavior factor of the structural systems. Additionally, damping, loading pattern, and material 
deformation are the other key parameters that influence this factor.

\subsection{Ductility capacity}

The most important parameter that affects the behavior factor of a structure is its ductility capacity. Recently, researchers have conducted extensive studies on this factor. Among these research studies, ATC19 [23] recommended using the relations developed by Nassar and Krawinkler [24], Miranda [25], and Newmark and Hall [26]. Accordingly, ductility is determined through the following equation [23]:

$$
\mu=\frac{\Delta_{m}}{\Delta_{y}}
$$

where $\Delta_{m}$ and $\Delta_{y}$ are the maximum relative and relative yield lateral displacements, respectively. Up to now, various methods have been proposed for the estimation of ductility factor. However, this section is limited to introducing three well-known approaches developed in [24-26]. Nassar and Krawinkler [24] proposed a formula whose components are ductility, fundamental period, and material deformation. This relation has the subsequent form [23]:

$$
R_{\mu}=[C \times(\mu-1)+1]^{\frac{1}{C}},
$$

where:

$$
C=\frac{T^{a}}{1+T^{a}}+\frac{b}{T}
$$

where $T$ is the fundamental period of the structure, and parameters $a$ and $b$ are dependent on strain hardening. These parameters are introduced in Table 1 [23].

The second well-known strategy was developed by Miranda [25]. The components of this formula are ductility and the fundamental period of the structure [23].

$$
R_{\mu}=\frac{\mu-1}{\phi}+1 \geq 1
$$

where $\phi$ is a function of $\mu, T$, and it depends on the soil type. For alluvial soil, this function has the succeeding form [23]:

$$
\phi=1+\frac{1}{12 \times T-\mu T}-\frac{2}{5 \times T} e^{\left[-2(\ln T-1 / 5)^{2}\right]} .
$$

The third method was proposed by Newmark and Hall [26]. In this scheme, the ductility and the

Table 1. Parameters $a$ and $b$ [23].

\begin{tabular}{ccc}
\hline $\boldsymbol{\alpha}(\boldsymbol{\%})$ & $\boldsymbol{a}$ & $\boldsymbol{b}$ \\
\hline 0 & 1 & 0.42 \\
2 & 1 & 0.37 \\
10 & 0.8 & 0.29 \\
\hline
\end{tabular}

fundamental period of the structure are considered. In this method, the succeeding formulas are employed for computing the ductility factor [23]:

$$
\begin{array}{ll}
\phi R_{\mu}=1 & T<0.03 \mathrm{sec}, \\
R_{\mu}=\sqrt{2 \mu-1} & 0.12<T<0.5 \mathrm{sec}, \\
R_{\mu}=\mu & T>1 \mathrm{sec} .
\end{array}
$$

\subsubsection{Overstrength factor}

Common design codes are based on elastic behavior of structures. In reality, structures can behave inelastically prior to failure. Consequently, some structural members can deform plastically and gradually plastic hinges form in these elements. Although the formation of the hinges reduces the stiffness of the structure, it can still resist the applied loads. Increasing the applied loads leads to formation of more plastic hinges. As a result, the structure stiffness is reduced drastically. Hence, the structural system converts to a mechanism, and its stiffness tends to zero. In this situation, if its ductility demand exceeds the ductility capacity, the structure fails to resist the loads. Accordingly, the structures have overstrength, which is not usually considered in their preliminary design. This overstrength can be inserted into the design process through the overstrength factor denoted by $R_{s}$. This factor can be calculated be employing the next relation [23]:

$$
R_{s}=\frac{V_{o}}{V_{d}}
$$

where $V_{o}$ and $V_{d}$ denote the maximum base shear in actual behavior and the first significant yield strength, respectively.

\subsection{Additional constraint factor}

The additional constraint factor, which is denoted by $R_{r}$ in this paper, is employed in order to increase the safety factor of the seismic systems including several moment frames. In this research work, it is presumed that $R_{r}=1$ because only shear walls are studied.

\section{Modeling}

In general, researchers investigated the commercial office buildings with a plan shown in Figure 1 and different number of stories [20]. Note that the importance factors of buildings $(I)$ were assumed to be 1 , and these structures were considered to be located in Los Angeles city with $S_{1}=0.2 \mathrm{~g}$ and $S_{s}=0.76 \mathrm{~g}$. It should be added that the soil class was D. Accordingly, this paper assesses three buildings similar to those of the aforementioned researchers.

In this study, the first story height of the buildings is $4.57 \mathrm{~m}$ and that of the other stories is $3.65 \mathrm{~m}$. 


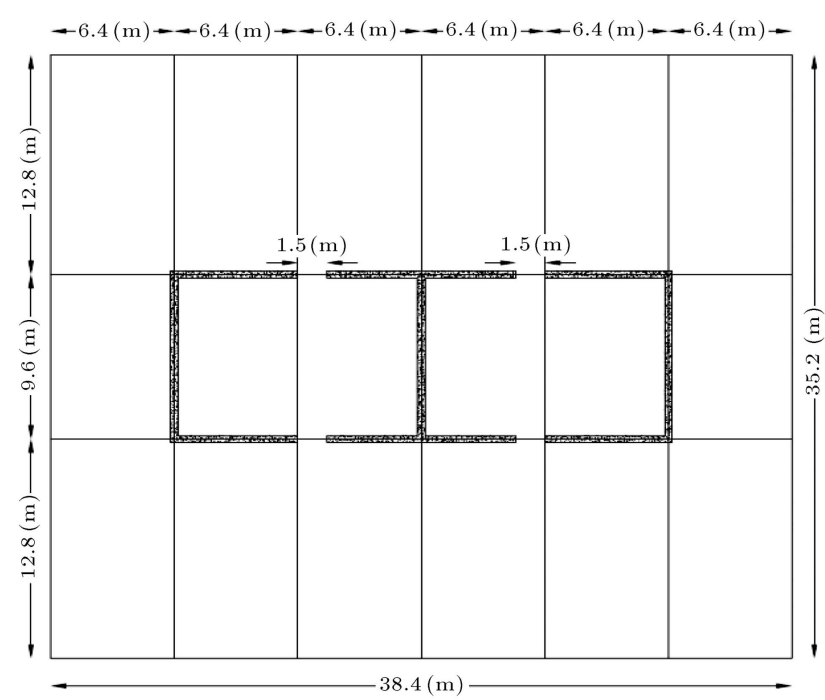

Figure 1. The plan of the building.

Moreover, the dead and live distributed loads applied to these structures are $250 \mathrm{~kg} / \mathrm{cm}^{2}$ and $250 \mathrm{~kg} / \mathrm{cm}^{2}$, respectively, based on the ASCE7-05 code. Furthermore, the floors are assumed to be rigid and regular. Besides, the mass of the buildings is uniformly distributed among stories. It should be noted that torsion does not occur in the aforesaid buildings and the characteristics of the materials are the same as those of the ones in the research of Hassan and El-Tawil [27].

Three-dimensional models of the buildings were generated and analyzed in ETABS9.6. Of note, these shear walls were designed based on ACI318-05 code [19]. After designing the structures, the 2D model of their walls was generated and investigated by Seismostruct software to reduce the computational efforts. The structures were symmetrical. In what follows, the flexural, shear, and shear-flexural behaviors of the coupling steel beam of 6-, 12-, and 20-story buildings were studied. As previously mentioned, the effects of beams length and their coupling ratios were evaluated in this work. To this end, different beams with $0 \%, 30 \%, 45 \%$, and $60 \%$ coupling ratios and different lengths were considered. As reported by ElTawil et al. [20], a coupling ratio of more than $60 \%$ is not suggested; consequently, in this study, structures were designed and analyzed at coupling ratios of up to $60 \%$.

\subsection{Seismic load}

The seismic loads applied to the structure were calculated based on the ASCE7-05 code. To compute these forces, the following relations were employed [18]:

$$
\begin{aligned}
& V=W \times C_{s}, \\
& C_{s}=S_{d} /(R \times I),
\end{aligned}
$$

$$
\begin{aligned}
& F_{x}=V \times \frac{W_{x} \times h_{x}^{k}}{\sum W_{x} \times h_{x}^{k}}, \\
& V_{\text {beam }}=\frac{O T M \times C R}{N \times L} .
\end{aligned}
$$

In Eqs. (12) and (13), $V$ denotes the base shear in which the structural weight and seismic coefficient are denoted by $W$ and $C_{s}$, respectively. Moreover, the response spectrum, the suggested behavior factor by the code, and importance factor are shown by $S_{d}$, $R$, and $I$, respectively. In Eq. (14), the lateral force designated for the $x$ th story of the building, $F_{x}$, is calculated using the total base shear $(V)$ as well as the weight $\left(W_{x}\right)$ and height $\left(h_{x}\right)$ of the same story of the building. In this equation, the power $k$ is calculated based on the time period of the building. The shear value of the coupling beam, $V_{\text {beam }}$, in Eq. (15) is linked to the overturning moment, coupling ratio, number of stories, and the distance between the rigidity centers of the walls, which are shown by $O T M, C R, N$, and $L$, respectively. For the 12-story building, the earthquake forces are given in Table 2. Note that the design force of each beam depends on its coupling ratio. This force is computed through Eq. (15).

\subsection{Design of the coupling beams}

Based on AISC341 [28] code, the coupling beams are designed. In what follows, the shear, flexural, and shear-flexural coupling beams are denoted by S, F, and FS, for simplicity. The characteristics of the designed beams of the 12-story building at different coupling ratios are given in Table 3 . According to AISC341 [28] code, the behavior of the beams is specified using the following inequalities [28]:

$$
\begin{aligned}
& g \leq \frac{1.6 \times M_{c e}}{V_{c e}}, \\
& g \geq \frac{2.6 \times M_{c e}}{V_{c e}},
\end{aligned}
$$

where plastic moment, plastic shear force of the beam, and effective length are $M_{c e}, V_{c e}$, and $g$, respectively. To design shear and flexural beams, Eqs. (16) and

Table 2. The earthquake forces and overturning moment of the 12-story building.

\begin{tabular}{cccccc}
\hline Story & $\begin{array}{c}\boldsymbol{F}_{\boldsymbol{x}} \\
(\text { Ton })\end{array}$ & $\begin{array}{c}\boldsymbol{O T M} \\
(\text { Ton-m) }\end{array}$ & Story & $\begin{array}{c}\boldsymbol{F}_{\boldsymbol{x}} \\
\text { (Ton) }\end{array}$ & $\begin{array}{c}\boldsymbol{O T M} \\
(\text { Ton-m) }\end{array}$ \\
\hline 1 & 11 & 9235 & 7 & 106 & 1991 \\
2 & 22 & 7879 & 8 & 126 & 1324 \\
3 & 36 & 6335 & 9 & 147 & 807 \\
4 & 52 & 4983 & 10 & 169 & 431 \\
5 & 69 & 3811 & 11 & 192 & 182 \\
6 & 87 & 2819 & 12 & 206 & 49 \\
\hline
\end{tabular}


Table 3. The characteristics of the coupling beam of the 12-story building.

\begin{tabular}{ccccc}
\hline $\begin{array}{c}\text { Coupling } \\
\text { beam }\end{array}$ & $\begin{array}{c}\text { Beam } \\
\text { height } \\
\text { (cm) }\end{array}$ & $\begin{array}{c}\text { Web } \\
\text { thickness }\end{array}$ & $\begin{array}{c}\text { Flange } \\
\text { width }\end{array}$ & $\begin{array}{c}\text { Flange } \\
\text { thickness } \\
\text { (cm) }\end{array}$ \\
\hline S-30\% & 26.4 & 0.8 & 16.5 & 2.5 \\
S-45\% & 40 & 0.8 & 16.5 & 2.5 \\
S-60\% & 54.5 & 0.8 & 16.5 & 2.5 \\
F-30\% & 45 & 0.8 & 25 & 3.4 \\
F-45\% & 67 & 0.8 & 25 & 3.5 \\
F-60\% & 90.8 & 0.8 & 25 & 3.6 \\
FS-30\% & 31.5 & 0.8 & 16.5 & 3.2 \\
FS-45\% & 49.3 & 0.8 & 16.5 & 3.4 \\
FS-60\% & 66 & 0.8 & 16.5 & 3.4 \\
\hline
\end{tabular}

(17) should be satisfied, respectively. To design the shear-flexural beams, the following inequalities should be satisfied [28].

$$
\frac{1.6 \times M_{c e}}{V_{c e}}\left\langleg \left\langle\frac{2.6 \times M_{c e}}{V_{c e}} .\right.\right.
$$

\subsection{Design of the walls}

To design the walls, it is required to perform linear analysis. In this process, the $P-\Delta$ and cracking effects should be considered. For this purpose, ETABS software is utilized. As a design recommendation, plastic hinges of beams should form before those of the walls. To consider the nonlinear effects of beams, their plastic shear forces and moments are manually calculated. Then, equivalent forces are applied to the walls for their design [20]. The middle (T-shaped) and sidelong (L-shaped) wall sections of the 12-story building are shown in Figures 2 and 3, respectively. The length of boundary elements and their required bars are listed in Tables 4 and 5,

respectively. It is worthwhile to remark that the thickness of walls $(35 \mathrm{~cm})$ on different stories of the structures does not change. In this way, the stiffness variation is minimized.

After designing the walls, the nonlinear static

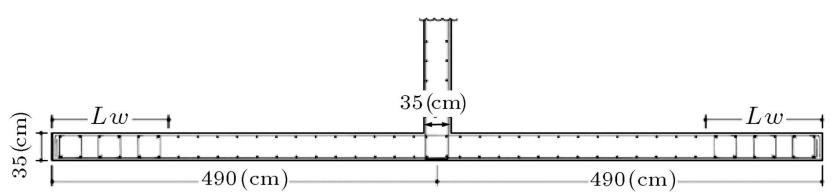

Figure 2. The section of the middle wall (T-shaped).

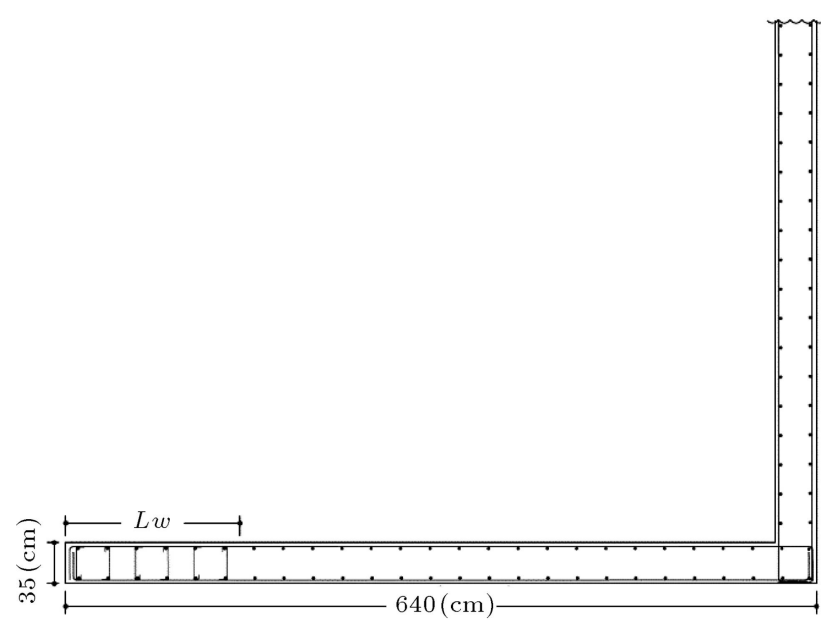

Figure 3. The section of the sidelong wall (L-shaped).

analysis was applied to them. Based on the achieved results, the behavior factor was estimated. For this purpose, Seismostruct software was employed.

\subsection{Nonlinear static analysis of shear walls}

After designing the walls and coupling beams, they were modeled in Seismostruct software. The nonlinear static analysis was carried out. In the developed models, the weight of each story of the designated building was considered as separate lumped masses on the top of each shear wall. Of note, the 2D model of the walls was generated in the software. The models include three column elements. According to AIC318 [19], half of the wall whose length is equal to the effective width of the wall should be modeled. Seismostruct software takes advantage of the equivalent frame and fiber approach to analyzing the walls.

In this paper, when the overall instability of the structure or failure of a structural elements occurs, the

Table 4. The length of boundary elements of the middle (T-shaped) wall of the 12-story building.

\begin{tabular}{ccccccccccc}
\hline & \multicolumn{10}{c}{$\boldsymbol{c} \boldsymbol{c} \boldsymbol{c}(\mathbf{m})$} \\
\cline { 2 - 11 } Story & $\mathbf{S}$ & $\mathbf{S}$ & $\mathbf{S}$ & $\mathbf{F}$ & $\mathbf{F}$ & $\mathbf{F}$ & $\mathbf{F S}$ & $\mathbf{F S}$ & FS & No \\
& $\mathbf{3 0 \%}$ & $\mathbf{4 5 \%}$ & $\mathbf{6 0 \%}$ & $\mathbf{3 0 \%}$ & $\mathbf{4 5 \%}$ & $\mathbf{6 0 \%}$ & $\mathbf{3 0 \%}$ & $\mathbf{4 5 \%}$ & $\mathbf{6 0 \%}$ & coupling \\
\hline 1 & 2 & 2 & 2 & 2 & 2 & 2 & 2 & 2 & 2 & 2 \\
2 & 2 & 2 & 2 & 2 & 2 & 2 & 2 & 2 & 2 & 2 \\
3 & 1 & 1 & 1 & 1 & 1 & 1 & 1 & 1 & 1 & 2 \\
4 & - & - & - & - & - & - & - & - & - & 1 \\
5 & - & - & - & - & - & - & - & - & - & 1 \\
$6-12$ & - & - & - & - & - & - & - & - & - & - \\
\hline
\end{tabular}


Table 5. The number of required bars of the middle (T-shaped) wall of the 12-story building.

\begin{tabular}{|c|c|c|c|c|c|c|c|c|c|c|}
\hline \multirow{3}{*}{ Story } & \multicolumn{10}{|c|}{ Number of bars } \\
\hline & $\mathrm{S}$ & $\mathrm{S}$ & $\mathbf{S}$ & $\mathbf{F}$ & $\mathbf{F}$ & $\mathbf{F}$ & FS & FS & FS & No \\
\hline & $30 \%$ & $45 \%$ & $60 \%$ & $30 \%$ & $45 \%$ & $60 \%$ & $30 \%$ & $45 \%$ & $60 \%$ & coupling \\
\hline 1 & 35 & 36 & 36 & 20 & 20 & 15 & 15 & 15 & 15 & 20 \\
\hline 2 & 25 & 25 & 25 & 15 & 15 & 10 & 10 & 10 & 10 & 20 \\
\hline 3 & 10 & 10 & 10 & 5 & 5 & 5 & 5 & 5 & 5 & 10 \\
\hline 4 & - & - & - & - & - & - & - & - & - & 10 \\
\hline 5 & - & - & - & - & - & - & - & - & - & 10 \\
\hline $6-12$ & - & - & - & - & - & - & - & - & - & - \\
\hline
\end{tabular}

analysis process is stopped. Furthermore, if the plastic rotation of the coupling beams reaches their maximum allowable based on AISC341-05 [28], the analysis will be interrupted. Moreover, the analysis is ceased when the maximum allowable lateral displacement of the roof is achieved. The lateral displacement is selected as $1.5 \%$ of the total height of the building.

Accordingly, for the twelve-story building with a coupling ratio of $60 \%$, the base shear variation versus the displacement of the building roof is depicted in Figure 4. Moreover, Eurocode 8 [29] suggests a bilinear curve that fits based on the equivalence of the area discrepancy above and below the original curve, assuming an elastic-perfectly plastic idealized behavior, see Figure 4. This approach is similar to the original N2 method [30]. Of note, the aforementioned curves for all models were obtained considered in this paper, which are not presented for brevity.

According to the bilinear diagram, the maximum and yielding relative lateral displacements $\left(\Delta_{m}\right.$ and

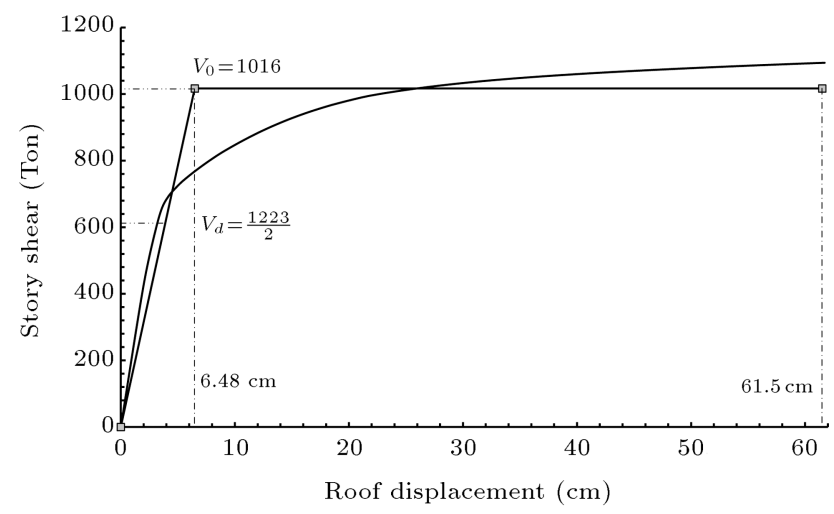

Figure 4. 12-story building with a $60 \%$ coupling ratio and shear-flexural beam.
$\left.\Delta_{y}\right)$ are $61.5 \mathrm{~cm}$ and $6.48 \mathrm{~cm}$, respectively, and $\mu$ is equal to 9.49 .

Except for Uang's approach, the other tactics require $R_{s}$ and $R_{r}$ and they are calculated and assumed to be 1.66 and 1.00 , respectively. Based on the results of nonlinear analysis, the behavior factor of the buildings can be calculated by employing the aforesaid schemes. For estimating this factor, the required parameters of each strategy are listed in Table 6 .

\section{Results}

In this research, the behavior factor was estimated by four methods: Uang's [22] scheme, Nassar and Krawinkler [24], Miranda [25], Newmark and Hall [26] strategies. Tables 7-9 present the behavior factors of 6-, 12-, and 20-story buildings, respectively. Note that beams with different behavior are utilized in these structures.

The behavior factor of buildings with flexural beams is less than that of other buildings. Moreover, decreasing the coupling ratio reduces the behavior factor.

Besides, the behavior factors of buildings with uncoupled walls are smaller than those of other buildings.

Based on the comparison of the behavior factors of 6-, 12-, and 20-story buildings, it can be concluded that the coupling ratio plays a more important role in taller buildings with flexural beams. Additionally, an increase in the coupling ratio intensifies the behavior factor of all buildings.

According to these tables, the behavior factors of walls with shear beams are greater than those of walls with flexural beams. This is because the allowable rotation and energy absorption of the shear beams are higher than those of the flexural beams.

Table 6. Required parameters for calculate behavior factor.

\begin{tabular}{|c|c|c|c|c|c|c|c|c|c|c|c|}
\hline \multicolumn{3}{|c|}{ Uang } & \multicolumn{4}{|c|}{ Krawinkler } & \multicolumn{3}{|c|}{ Miranda } & \multicolumn{2}{|c|}{ New mark } \\
\hline$V_{e}$ & $V_{s}$ & $\boldsymbol{R}$ & $b$ & $c$ & $\boldsymbol{R}_{\mu}$ & $\boldsymbol{R}$ & $\varphi$ & $\boldsymbol{R}_{\mu}$ & $R$ & $\boldsymbol{R}_{\mu}$ & $R$ \\
\hline $5.0 \mathrm{e}+6$ & $4.9 \mathrm{e}+5$ & 10.14 & 0.42 & 0.90 & 11.04 & 18.35 & 1.00 & 9.49 & 15.78 & 9.49 & 15.78 \\
\hline
\end{tabular}


Table 7. Behavior factors of 6-story buildings.

\begin{tabular}{|c|c|c|c|c|c|c|c|c|c|c|}
\hline \multirow{3}{*}{ Method } & \multicolumn{10}{|c|}{ 6-story buildings } \\
\hline & \multirow{2}{*}{$\begin{array}{l}\text { Uncoupled } \\
\text { walls }\end{array}$} & \multicolumn{3}{|c|}{ Shear beams } & \multicolumn{3}{|c|}{ Flexural-shear beams } & \multicolumn{3}{|c|}{ Flexural beams } \\
\hline & & $30 \%$ & $45 \%$ & $60 \%$ & $30 \%$ & $45 \%$ & $60 \%$ & $30 \%$ & $45 \%$ & $60 \%$ \\
\hline Miranda & 6.77 & 9.25 & 8.40 & 12.14 & 9.79 & 11.06 & 9.08 & 5.93 & 6.59 & 7.78 \\
\hline Newmark & 5.74 & 8.00 & 9.54 & 9.40 & 6.82 & 8.24 & 10.37 & 4.27 & 4.75 & 5.52 \\
\hline Krawinkler & 6.23 & 12.81 & 15.54 & 14.83 & 10.38 & 12.88 & 16.91 & 5.59 & 6.21 & 7.35 \\
\hline Uang & 3.51 & 8.54 & 8.06 & 11.77 & 11.84 & 11.79 & 11.63 & 8.86 & 10.21 & 10.63 \\
\hline Average & 5.56 & 9.65 & 10.38 & 12.04 & 9.71 & 10.99 & 12.00 & 6.16 & 6.94 & 7.82 \\
\hline
\end{tabular}

Table 8. Behavior factors of 12 -story buildings.

\begin{tabular}{|c|c|c|c|c|c|c|c|c|c|c|}
\hline \multirow{3}{*}{ Method } & \multicolumn{10}{|c|}{ 12-story buildings } \\
\hline & \multirow{2}{*}{$\begin{array}{l}\text { Uncoupled } \\
\text { walls }\end{array}$} & \multicolumn{3}{|c|}{ Shear beams } & \multicolumn{3}{|c|}{ Flexural-shear beams } & \multicolumn{3}{|c|}{ Flexural beams } \\
\hline & & $30 \%$ & $45 \%$ & $60 \%$ & $30 \%$ & $45 \%$ & $60 \%$ & $30 \%$ & $45 \%$ & $60 \%$ \\
\hline Miranda & 3.80 & 10.89 & 14.48 & 24.19 & 10.18 & 9.66 & 15.78 & 4.18 & 5.25 & 7.95 \\
\hline Newmark & 3.25 & 9.22 & 13.06 & 19.65 & 8.61 & 7.93 & 15.78 & 3.46 & 4.32 & 6.48 \\
\hline Krawinkler & 3.42 & 10.38 & 14.98 & 23.61 & 9.67 & 8.71 & 18.35 & 3.61 & 4.53 & 6.95 \\
\hline Uang & 3.20 & 7.53 & 5.88 & 8.45 & 8.51 & 6.55 & 10.14 & 4.91 & 5.32 & 6.24 \\
\hline Average & 3.42 & 9.50 & 12.10 & 18.97 & 9.24 & 8.21 & 15.01 & 4.04 & 4.85 & 6.91 \\
\hline
\end{tabular}

Table 9. Behavior factors of 20-story buildings.

\begin{tabular}{|c|c|c|c|c|c|c|c|c|c|c|}
\hline \multirow{3}{*}{ Method } & \multicolumn{10}{|c|}{ 20-story buildings } \\
\hline & \multirow{2}{*}{$\begin{array}{l}\text { Uncoupled } \\
\text { walls }\end{array}$} & \multicolumn{3}{|c|}{ Shear beams } & \multicolumn{3}{|c|}{ Flexural-shear beams } & \multicolumn{3}{|c|}{ Flexural beams } \\
\hline & & $30 \%$ & $45 \%$ & $60 \%$ & $30 \%$ & $45 \%$ & $60 \%$ & $30 \%$ & $45 \%$ & $60 \%$ \\
\hline Miranda & 3.34 & 7.18 & 8.24 & 9.24 & 7.16 & 10.05 & 12.79 & 2.87 & 4.33 & 8.29 \\
\hline Newmark & 2.88 & 6.24 & 7.03 & 8.00 & 6.14 & 8.89 & 12.22 & 2.49 & 3.69 & 7.10 \\
\hline Krawinkler & 3.00 & 7.05 & 7.77 & 9.01 & 6.85 & 10.16 & 14.28 & 2.58 & 3.90 & 7.92 \\
\hline Uang & 3.32 & 6.07 & 6.80 & 6.70 & 6.09 & 5.43 & 7.29 & 2.97 & 3.41 & 5.17 \\
\hline Average & 3.14 & 6.63 & 7.46 & 8.24 & 6.56 & 8.63 & 11.64 & 2.73 & 3.83 & 7.12 \\
\hline
\end{tabular}

As shown in Figure 5, the effects of the coupling ratio on the behavior factor of the 6-, 12-, and 20-story buildings are assessed. In addition, this figure investigates the influence of the aforesaid parameter on the average behavior factor of these buildings. On average,

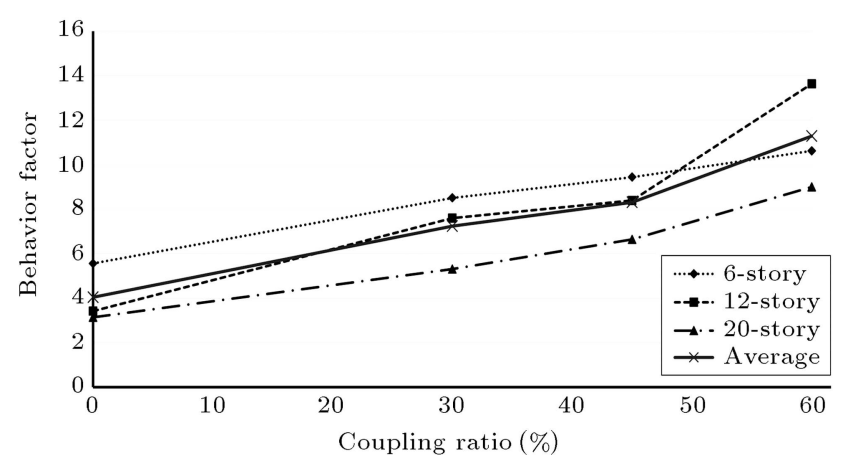

Figure 5. Coupling ratio-behavior factor relationship. by increasing the coupling ratio from zero to $60 \%$, the behavior factor increases from about 4 to about 11 .

Figure 6 investigates the effect of the building height and coupling beam on the behavior factor. It is seen that on average, the behavior factor of shear

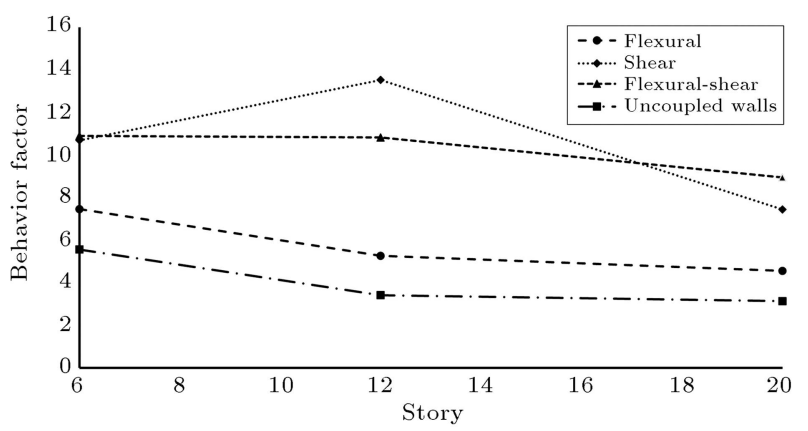

Figure 6. The story elevation-behavior factor relationship. 
walls is reduced by increasing the number of stories.

It is also shown that the behavior factor of uncoupled walls is less than that of the coupling shear walls. Moreover, the behavior of the coupling beam affects the behavior factor such that the shear walls connected by beams have the most $R$ and the walls with flexural beams have the last $R$.

\section{Conclusions}

In this paper, the behavior factor of coupled walls with steel coupling beams was investigated for 6-, 12-, and 20-story buildings. The most important parameters such as height of the building, behavior of the coupling beam, and the coupling ratio were studied and compared. The results showed a proper combination of building height, coupling ratio, and the behavior coupling beam.

Herein, the findings of this research work are summarized as follows:

1. The obtained results showed that the behavior factor of the coupled shear walls was greater than that of the uncoupled ones. In other words, it can be observed that on average, the behavior factor of the walls with $30 \%, 45 \%$, and $60 \%$ was $1.79,2.06$, and 2.79 times the behavior factor of uncoupled shear walls, respectively;

2. Increasing the number of stories from six to twenty stories results in a $39 \%$ reduction in the behavior factor of the shear walls, on average. However, this reduction in the case of shear walls containing shear coupling beams is less than that with flexural coupled beams;

3. The behavior factor of the buildings shear coupling beams was greater than that of the buildings with the flexural ones. On average, the behavior factors of walls with shear coupling beams were 1.39 times the behavior factors of walls with flexural coupling beams. However, the behavior factor of the coupled walls with flexural beams was not greater than that of the uncoupled walls, while the behavior factor of the coupled shear walls with shear beams and flexural-shear beams was 1.73 times that of the uncoupled walls in the worst case.

\section{References}

1. Bengar, H.A. and Aski, R.M. "Effect of steel and concrete coupling beams on seismic behavior of RC frame accompanied with coupled shear walls", Scientia Iranica, Transaction A, Civil Engineering, 24(5), pp. 2227-2241 (2017).

2. Hakimi, S. and Madandoust, R. "Numerical study on coupling beam retrofitted using CFRP and GFRP sheets", American Journal of Engineering and Applied Sciences, 11(3), pp. 1125-1129 (2018). DOI: 10.3844/a jeassp. 201

3. Pulay, T. and Priestley, M.N. Seismic design of reinforced concrete and masonry buildings, ISBN: 978-0471-54915-4 (1975).

4. Harries, K.A., Seismic Design and Retrofit of Coupled Walls using Structural Steel, McGill University Libraries (1995).

5. Gong, B. and Shahrooz, B.M. "Concrete-steel composite coupling beams. II: Subassembly testing and design verification", Journal of Structural Engineering, 127(6), pp. 632-638 (2001).

6. Su, R. and Zhu, Y. "Experimental and numerical studies of external steel plate strengthened reinforced concrete coupling beams", Engineering Structures, 27(10), pp. 1537-1550 (2005).

7. Harries, K.A. and McNeice, D.S. "Performance-based design of high-rise coupled wall systems", The Structural Design of Tall and Special Buildings,15(3), pp. 289-306 (2006).

8. Shen, Q., Kurama, Y.C., and Weldon, B.D. "Seismic design and analytical modeling of posttensioned hybrid coupled wall subassemblages", Journal of Structural Engineering, 132(7), pp. 1030-1040 (2006).

9. Fortney, P.J., Shahrooz, B.M., and Rassati, G.A. "Large-scale testing of a replaceable "fuse" steel coupling beam", Journal of Structural Engineering, 133(12), pp. 1801-1807 (2007).

10. El-Tawil, S., Harries, K., Fortney, J.P., et al. "Seismic design of hybrid coupled wall systems: state of the art”, Journal of Structural Engineering, 136(7), pp. 755-769 (2010).

11. Deng, Z., Xu, C., Zeng, J., et al. "Investigation on the structural behavior of shear walls with steel truss coupling beams under seismic loading", Advances in Materials Science and Engineering, 2018, Article ID 5602348 (2018). DOI: $10.1155 / 2018 / 5602348$

12. Louzai, A. and Abed, A. "Evaluation of the seismic behavior factor of reinforced concrete frame structures based on comparative analysis between non-linear static pushover and incremental dynamic analyses", Bulletin of Earthquake Engineering, 13(6), pp. 17731793 (2015).

13. Soltangharaei, V., Razi, M., and Gerami, M. "Comparative evaluation of behavior factor of SMRF structures for near and far fault ground motions", Periodica Polytechnica Civil Engineering, 60(1), pp. 75-82 (2016).

14. Issa, M.S. and Issa, H.M. "Application of pushover analysis for the calculation of behavior factor for reinforced concrete moment-resisting frames", International Journal of Civil and Structural Engineering, 5(3), p. 216 (2015).

15. Hung, C.-C. and Lu, W.-T. "Tall hybrid coupled structural walls: seismic behavior and design suggestions", International Journal of Civil Engineering, 16(5), pp. 567-582 (2018). 
16. Hung, C.-C. and Lu, W.-T. "A performance-based design method for coupled wall structures", Journal of Earthquake Engineering, 21(4), pp. 579-603 (2017).

17. Das, R., Zona, A., Vandoren, B., et al. "Optimizing the coupling ratio of seismic resistant HCW systems with shear links", Journal of Constructional Steel Research, 147, pp. 393-407 (2018).

18. ASCE 7-05, American Society of Civil Engineers: Reston, VA: ASCE (2005).

19. ACI 318, American Concrete Institute (ACI) Committee 318 (2005).

20. El-Tawil, S., Fortney, J.P., Harries, K., et al., Recommendations for Seismic Design of Hybrid Coupled Wall Systems, American Society of Civil Engineers (2009).

21. Vona, M. and Mastroberti, M. "Estimation of the behavior factor of existing RC-MRF buildings", Earthquake Engineering and Engineering Vibration, 17(1), pp. 191-204 (2018).

22. Uang, C.-M. "Establishing R (or R w) and $\mathrm{C} \mathrm{d}$ factors for building seismic provisions", Journal of Structural Engineering, 117(1), pp. 19-28 (1991).

23. ATC-19 "Structural response modification factors", ATC Report 19 (1995).

24. Nassar, A. and Krawinkler, H. "Seismic demands for SDOF and MDOF systems", John Blume Earthquake Engineering Ctr. Dept. of Civil Engineering, Rep. 95. 1991, Stanford University, Stanford, California (1991).

25. Miranda, E. "Site-dependent strength-reduction factors", Journal of Structural Engineering, 119(12), pp. 3503-3519 (1993).

26. Newmark, N.M. and Hall, W.J. "Seismic design criteria for nuclear reactor facilities", in Proc World Conf. Earthquake Eng., B-4 (1969).
27. Hassan, M. and El-Tawil, S. "Inelastic dynamic behavior of hybrid coupled walls", Journal of Structural Engineering, 130(2), pp. 285-296 (2004).

28. AISC 341-05, Seismic Provisions for Structural Steel Buildings, American Institute of Steel Construction (2005).

29. Cen, E., 8. "Design of structures for earthquake resistance. Part 1: general rules", Seismic Actions and Rules for Buildings, European Standard EN 1998-1, Comité Européen de Normalisation (2004).

30. Fajfar, P. and Fischinger, M. "N2-A method for nonlinear seismic analysis of regular buildings", 9th World Conference in Earthquake Engineering (1988).

\section{Biographies}

Mohammad Hasan Daneshvar has been a PhD student at Islamic Azad University of Isfahan since September 2013. He received his BS degree in Civil Engineering from Islamic Azad University of Mashhad in September 2009 and obtained his MS degree in Structural Engineering from Ferdowsi University of Mashhad (FUM) in September 2012 with a minor in Structural Engineering.

Abbas Karamodin received his BS and MS degrees in Structural Engineering from the University of Tehran (UT) in 1986 and his PhD degree in Structural Engineering from Ferdowsi University of Mashhad (FUM) in 2009 with a minor in Structural Control. He has served in FUM as a faculty member, since 1987. He has had 3 books published in his related field and several papers in respectable journals and conference proceedings. His areas of research are earthquake engineering and structural control. 